\title{
O FUNDAMENTO ONTOLÓGICO DA AUTONOMIA EM KANT
}

\author{
[THE ONTOLOGICAL FOUNDATION OF AUTONOMY IN KANT]
}

Rogério Vaz Trapp *

Universidade Federal da Fronteira Sul

\begin{abstract}
RESUMO: no presente trabalho pretendemos demonstrar que o fundamento da filosofia teórica e prática de Kant reside na estrutura dos princípios da Lógica, motivo pelo qual a própria Lógica acaba por elevar-se à condição de fundamento metafísico da filosofia kantiana e estrutura da realidade fenomênica. Com isso, a explicação tanto da lei da causalidade natural como da causalidade pela liberdade será compreendida a partir da aplicação do princípio de razão suficiente ou à fillosofia teórica ou à filosofia prática.
\end{abstract}

Palavras-chaVe: Lógica; Ontologia; Kant
ABSTRACT: The present paper tries to demonstrate that the basis of Kant's theoretical and practical philosophy lies on the structure of the principles of logic, the reason why logic itself is elevated to the condition of metaphysical basis of Kant's philosophy and structure of phenomenal reality. Thereby, the explanation of both the law of natural causality and causality of freedom is understood through the application of the principle of sufficient reason or theoretical philosophy or practical philosophy.

KEYWORDS: Logic; Ontology; Kant

\section{INTRODUÇÃo}

Com a Crítica da Razão Pura, obra que inaugura a filosofia crítica, Kant conhecimento de si mesma e da constituição de um tribunal que lhe assegure as pretensões legítimas e, em contrapartida, possa condenar-lhe todas as pretensões infundadas"(AXI - XII,1997). Citação clássica, na Introdução da CRP, já indica o período que essa filosofia inaugura: o Criticismo. Inaugura-o, porém, não simplesmente porque é a primeira das obras kantianas desse período, antes e acima disso, a primeira crítica é a obra na qual Kant expõe os fundamentos do sistema do Idealismo transcendental. Caygill comenta a esse respeito, que a CRP apresenta "as reflexões maduras de Kant sobre metafísica, epistemologia, cosmologia, psicologia e teologia, e tornou-se célebre como o texto que fundou a 'filosofia crítica' e 'transcendental"' (2000, verbete CRÍTICA DA RAZÂO PURA).

Enquanto método de investigação, o Idealismo transcendental estabelece as possibilidades e limites do conhecimento científico. Como método, metafísica e epistemologia, a $C R P$ fundamenta a condição de possibilidade de todo o edifício crítico. Portanto, com a avaliação que se fizer dela, cai ou se mantém o edifício da

* Doutorado em Filosofia pela Pontifícia Universidade Católica do Rio Grande do Sul (2011 - Capes 6). Professor adjunto da Universidade Federal da Fronteira Sul, em SantaCatarina.m@ilto: rogerio.trapp@uffs.edu.br 
Filosofia transcendental.

Não seria difícil para o leitor concordar com isso, pois é mais ou menos o caminho por onde vão muitas das interpretações correntes. A primeira vista, o Idealismo transcendental é um método, pois pretende realizar um autoexame sistemático da razão com o fim de determinar as fontes e o alcance de seus conceitos a priori, e de atuar como um cânone contra sua inadequada extensão para além dos limites da experiência possível (Kant, 1997, AXI, AXVII, BXXII). Dizer que ela é uma reformulação da metafísica wolffiana também não traria grandes contestações, contudo, estabelecer em que sentido ela é uma reformulação da metafísica e, portanto, ainda uma metafísica, isso sim traria muitas discussões não livres do debate acalorado.

Evidentemente este autor não pretende resolver aqui a contenda - e nem mesmo o poderia - mas, antes, partir da possibilidade da ideia de que a Filosofia transcendental é uma reformulação da metafísica wolffiana, e explorar os resultados que ela pode nos trazer. A esse respeito podemos acrescentar importantes comentários, como aqueles que Caygill (2000) apresenta em seu Dicionário Kant. Nesta obra, sob o verbete 'Crítica da Razão Pura', o autor comenta que esta obra pode ser lida "como a análise das partes de uma "faculdade cognitiva", sob um viés epistemológico, portanto; ou em "função da análise de uma forma peculiar de juízo, na qual o predicado amplia o significado de seu sujeito e o faz de um modo cuja validade universal e necessária pode ser demonstrada"; mas também como a "desconstrução da metafísica tradicional". Epistemologia, lógica e metafísica parecem, assim, confundirem-se no desenvolvimento da CRP. Com efeito, ainda segundo o autor do dicionário, "cada uma dessas leituras tem alguma verdade, uma boa dose dela quando todas reunidas, mas não esgotam a gama de interesses explorados".

Mais adiante um pouco, ainda em Caygill, e poderemos ler, sob o verbete 'metafísica', que

no período imediatamente anterior a Kant, o conteúdo da metafísica tinha-se fixado em quatro seções: a primeira era a metafísica geral ou ontologia, a qual se ocupava, nas palavras da metafísica de Wolff, com 'os alicerces do nosso saber e das coisas em geral'; as três restantes eram os 'objetos e ciências da metafísica especial', a saber, (a) a alma e a psicologia, (b) o mundo e a cosmologia, e (c) Deus e a teologia. Kant seguiu de perto esse esquema na CRP, com a 'Analítica transcendental' tratando criticamente da ontologia e as três seções da 'Dialética transcendental' estudando as três partes da metafísica especial (2000).

É precisamente dentro dessa ideia que pretendemos nos situar, isto é, de que a primeira parte da CRP, mais especificamente, a Analítica transcendental, trata da Ontologia ou Metafísica geral wolffiana, no sentido de investigação que se ocupa com os alicerces de nosso saber e das coisas em geral. $O$ próprio Kant sugere isto ao escrever que "o orgulhoso nome de ontologia, que se arroga a pretensão de oferecer, em doutrina sistemática, conhecimentos sintéticos a priori das coisas em si tem de ser substituído pela mais modesta denominação de simples analítica do entendimento puro" (1997, B303). Ora, se considerarmos a Analítica transcendental como uma reelaboração da Ontologia ou Metafísica geral e se também levarmos em conta que apenas no século XIX surge a distinção entre Epistemologia e Ontologia, ou seja, "que a leitura da filosofia crítica como um projeto epistemológico é uma interpretação anacrônica, post hoc" (Caygill, verbete EPISTEMOLOGIA, 2000), então poderemos considerá-la, a um só tempo, um tratado de Metafísica geral ou Ontologia e, por que Ontologia, também Epistemologia. Sempre, porém, no sentido da pergunta pelos alicerces de nosso saber e das coisas em geral.

Seguindo esse modelo teórico, dividimos a primeira parte da Lógica transcendental em Analitica transcendental e Dialética transcendental. A primeira 
tratando da Metafísica geral e a segunda, da Metafísica especial. A Analítica transcendental divide-se ainda em Analítica dos conceitos e Analítica dos princípios. Naquela, Kant empreende "a decomposição, ainda pouco tentada, da própria faculdade do entendimento, para examinar a possibilidade dos conceitos a priori, procurando-os somente no entendimento, como seu lugar de origem" (1997, B90). Nesta, isto é, na Analítica dos princípios, o filósofo procurará "apenas um cânone para a faculdade de julgar, que lhe ensina a aplicar aos fenômenos os conceitos do entendimento, que contêm as condições das regras a priori" (Id., B171). A Analítica dos princípios, enquanto doutrina transcendental da faculdade de julgar, divide-se ainda em dois outros capítulos, dos quais, o primeiro, "trata da condição sensível, a única que permite o uso dos conceitos do entendimento, isto é, do esquematismo do entendimento puro"; o segundo capítulo, por sua vez trata dos "juízos sintéticos que decorrem a priori (...) dos conceitos puros do entendimento e que constituem o fundamento de todos os outros conhecimentos a priori, ou seja, dos princípios do entendimento puro" (Ibid., B175).

Por esquema, entende Kant a "condição formal e pura da sensibilidade a que o conceito do entendimento está restringido no seu uso" (Ibid., B179). Nesse sentido, o esquematismo do entendimento puro é o "processo pelo qual o entendimento opera com esses conceitos" (Ibid.). Com efeito, para explicar a transição dos elementos da intuição para os conceitos do entendimento é que se fazem necessários, portanto, os esquemas e o esquematismo.

Os princípios do entendimento puro "têm este nome, não só porque contêm em si os fundamentos de outros juízos, mas também porque não assentam em conhecimentos mais elevados e de maior generalidade" (Ibid., B188). Dividem-se ainda em princípios de juízos analíticos e de juízos sintéticos. O princípio dos juízos analíticos é o princípio de não contradição, princípio esse que "é um critério universal, embora apenas negativo, de toda a verdade" (Ibid., B190). Para os juízos sintéticos, entretanto, o seu princípio supremo reza que "as condições da possibilidade da experiência em geral são, ao mesmo tempo, condições da possibilidade dos objetos da experiência" (Ibid., B197).

A Analítica transcendental, ao lado da Dialética transcendental, faz parte da Lógica transcendental, segunda parte da Doutrina transcendental dos elementos. Segundo Caygill, já antes citado (Id.), na $C R P$ estão as reflexões maduras de Kant sobre Metafísica, Epistemologia, Cosmologia, Psicologia e Teologia. Ora, Cosmologia, Psicologia e Teologia são os objetos de investigação da Dialética transcendental. Fora a dialética, temos ainda a Doutrina transcendental do método, que tratará da "determinação das condições formais de um sistema completo da razão pura" (Kant, 1997, B735-736), e as divisões restantes da Doutrina transcendental dos elementos. E é precisamente nessa última, mais especificamente, em sua primeira e segunda partes Estética transcendental e Lógica transcendental - que Kant se ocupará com a Metafísica e a Epistemologia. E é precisamente por isso, ou seja, por que é a Metafísica e a Epistemologia que aqui nos interessam, que na sequência nos ocuparemos mais com a Lógica transcendental.

\section{LógiCa, Metafísica e A FUndamentaÇão da Filosofia transCendental}

O conhecimento, no uso estrito do termo, como conhecimento da realidade fenomênica, na Filosofia transcendental, significa a síntese entre intuição e conceito ou matéria e forma. A intuição é produto da sensibilidade e, por ter a experiência como fundamento, não pode nos oferecer nem universalidade nem necessidade. Os conceitos, pelo contrário, se demonstrada sua aprioridade, conferem a necessidade e estrita universalidade que deve conter um conhecimento verdadeiro. E a parte da CRP que irá 
tratar dos conceitos puros é precisamente a Lógica transcendental.

Segundo o próprio Kant,

na presunção de que haja porventura conceitos que se possam referir a priori a objetos, não como intuições puras ou sensíveis, mas apenas como atos do pensamento puro, e que são, por conseguinte, conceitos, mas cuja origem não é empírica nem estética, concebemos antecipadamente a ideia de uma ciência do entendimento puro e do conhecimento de razão pela qual pensamos objetos absolutamente $a$ priori. Uma tal ciência, que determinaria a origem, o âmbito e o valor objetivo desses conhecimentos, deveria chamar-se lógica transcendental, porque trata das leis do entendimento e da razão, mas só na medida em que se refere a objetos a priori e não, como a lógica vulgar, indistintamente aos conhecimentos de razão, quer empíricos quer puros (1997, B81-82).

A Lógica transcendental trata, portanto, do conjunto de elementos a priori do conhecimento intelectual. Chama-se lógica porque se ocupa com as leis do entendimento e da razão; transcendental, porque estas leis referem-se a objetos a priori. Difere da lógica vulgar, que, na verdade,

"não é propriamente uma lógica, mas uma ciência antropológica que só tem princípios empíricos, na medida em que trata das regras do uso natural do entendimento e da razão, que só são conhecidas in concreto, logo sem consciência das mesmas in abstrato" (Kant, 1992, A12).

O contrário da lógica vulgar é a lógica científica. Esta lógica é definida como a "ciência das regras necessárias e universais do pensamento, que podem e devem ser conhecidas a priori, independentemente do uso natural do entendimento e da razão in concreto" (Id.). A lógica científica ocupa praticamente o mesmo campo ocupado tanto pela lógica geral, isto é, funciona como cânon formal para o conhecimento (Ibid), quanto pela lógica pura, na medida em que nessa "separamos o entendimento dos demais poderes da mente e consideramos o que ele faz por si só" (Ibid, A14). A Lógica transcendental, por sua vez, está, diríamos, entre a lógica vulgar e a lógica científica, pois se ela, ao modo da primeira, não abstrai de seus objetos, no entanto, tal como na segunda, se ocupa também com as leis 'necessárias e universais do pensamento, que podem e devem ser conhecidas a priori'.

Desse ponto de vista, isto é, do ponto de vista do Idealismo transcendental, na $C R P$, Kant fundamenta a realidade da lógica formal - ou geral, pura e científica - , por meio da Lógica transcendental, na medida em que essa lhe incorpora um objeto, isto é, um conteúdo retirado da experiência. Se a Lógica transcendental funda a realidade, segunda categoria modal, da lógica formal, ela, porém, no que diz respeito à sua autofundamentação, impõe a si mesma os seus limites. Pois não pode mais fazê-lo a partir de uma base transcendente, devido às próprias consequências retiradas da $C R P$. Mas também não pode fazê-lo a partir de si mesma, seguindo a metódica aberta pela $C R P$, já que ela, por não abstrair de seus conteúdos ou daquilo no qual estão amalgamados, não pode retirar nenhum princípio ou lei, isto é, nenhuma proposição com alcance universal e valor necessário que justifique os seus próprios princípios. Portanto, o único caminho ainda aberto para uma auto-justificação da Lógica transcendental, segundo o método crítico, passa pela sua decomposição em forma e matéria, por meio da qual isolamos a experiência e a consideramos apenas naquilo que possui de formal, horizonte a partir do qual podemos retirar princípios a priori e leis universais e necessárias.

Entretanto, o que há de formal na Lógica transcendental é precisamente aquilo que Kant chama de lógica geral e que, na medida em que é pura e científica, se identifica com a lógica formal. Portanto, segundo o mesmo método dedutivo utilizado por Kant, nos é lícito afirmar que, se a lógica formal, do ponto de vista do fato da Lógica transcendental, se evidencia como horizonte possível de sua fundamentação 
última, pelo lado da pretensão de sua legitimidade, a lógica formal se evidencia como horizonte necessário de sua fundamentação última, na medida em que é só por seu meio que conseguimos justificar a pretensão da Lógica transcendental, enquanto ciência que determina a origem, o âmbito e o valor objetivo dos conhecimentos de razão pelos quais pensamos objetos absolutamente a priori.

Demonstrado pela análise a possibilidade da lógica formal, enquanto condição $a$ priori da Lógica transcendental, nós abrimos espaço para também afirmar, mediante a dedução de sua legitimidade, a sua necessidade. Nesse sentido, a Lógica transcendental, enquanto fornece as regras universais e necessárias do pensamento humano em geral, já que o humano é sua condição de possibilidade e de toda a Filosofia transcendental, nos permite pensar, na medida em que pensar não é conhecer e na medida em que a experiência cognitiva nos fornece o dado com base no qual partir para nossa inferência, que as leis universais e necessárias do pensamento humano possam talvez ser também as leis universais e necessárias de todo e qualquer pensamento em geral, isto é, de todo o pensamento que possa existir para além do humano, nosso limite. Assim, estaria fundamentada tanto a necessidade da lógica formal para a nossa forma de pensar quanto a sua possibilidade como fundamento para toda forma de pensar em geral. Isto quer dizer, portanto, que podemos mudar a orientação do método dedutivo utilizado por Kant em ambas as três críticas, apresentado todavia de modo mais desenvolvido na primeira, para justificar a realidade objetiva e a necessidade lógica tanto das intuições puras quanto das categorias do entendimento, com a finalidade de conjecturar sobre o possível estatus metafísico da lógica formal, pois,

para que a imaginação não devaneie, mas conjecture debaixo da rigorosa vigilância da razão, é sempre necessário que se apoie previamente sobre qualquer coisa de absolutamente certo e não imaginário ou de simples opinião. Essa qualquer coisa é a possibilidade do próprio objeto. Então é permitido, pelo que respeita à realidade desse objeto, recorrer à opinião; mas esta opinião, para não ser sem fundamento, deve estar ligada, como princípio de explicação, ao que é realmente dado e portanto certo, e neste caso chama-se hipótese (Kant, 1997, B798).

Com efeito, "a parte da Lógica transcendental que apresenta os elementos do conhecimento puro do entendimento e os princípios, sem os quais nenhum objeto pode, em absoluto, ser pensado é a Analítica transcendental" (Ibid., B87). A lógica geral, por seu lado, é a "ciência das leis necessárias do entendimento e da razão em geral, ou - o que dá no mesmo - da mera forma do pensamento em geral" (Kant, 1992, A4). Assim, pois, na Lógica transcendental, porque ela não abstrai de seus conteúdos, "não se pode exigir nenhum critério geral de verdade do conhecimento, quanto à matéria, porque tal seria, em si mesmo, contraditório"(Kant, 1997, B23). Entretanto, segundo o próprio filósofo,

no que respeita, porém, ao conhecimento, considerado simplesmente segundo a mera forma (pondo de parte todo o conteúdo), é igualmente claro que uma lógica, na medida em que expõe as regras gerais e necessárias do entendimento, deverá nessas mesmas regras expor critérios de verdade. Tudo que os contradiga é falso, porque o entendimento assim estaria em contradição com as regras gerais de seu pensamento e, portanto, consigo mesmo. (...) Assim, o critério puramente lógico da verdade, ou seja, a concordância de um conhecimento com as leis gerais e formais do entendimento e da razão, é uma conditio sine qua non, por conseguinte a condição negativa de toda a verdade (Id., B83-84).

Ao modo da dualidade estrutural entre matéria e forma que percorre toda a crítica, podemos compreender que a Lógica transcendental, na medida em que não abstrai de seus conteúdos, opta não apenas por um conhecimento puro e formal, mas 
por um conhecimento como composto. Desse conhecimento, entretanto, quanto à matéria, não só "é completamente impossível e absurdo perguntar por uma característica da verdade", mas teremos mesmo de dizer que "não se pode exigir nenhum critério geral de verdade do conhecimento, quanto à matéria, porque tal seria, em si mesmo, contraditório" (Ibid.). A parte formal da Lógica transcendental é, contudo, pura e

pode pois chamar-se analítica e é, por isso mesmo, a pedra de toque, pelo menos negativa, da verdade, na medida em que, primeiramente, comprovar e avaliar com base nestas regras, todo o conhecimento, quanto à sua forma, antes de investigar o seu conteúdo para descobrir se em relação ao objeto contém uma verdade positiva (Ibid., B84-85).

Ora, a parte analítica da Lógica transcendental corresponde à lógica geral, enquanto "ciência das leis necessárias do entendimento e da razão em geral, ou (...) da mera forma do pensamento em geral" (Kant, 1992, A4). Logo, do ponto de vista do conhecimento como composto de intuição e conceito, como é o nosso caso, em que o acesso a objetos é sempre e necessariamente mediado, motivo pelo qual nunca podemos conhecer o objeto como é em si mesmo, no nosso caso, portanto, a lógica geral não pode nos fornecer a validade de um conhecimento, mas pode nos indicar o que ele não é. Se o conhecimento fosse possível para outros seres racionais como conhecimento meramente intelectual, a lógica geral seria não só uma lógica da mais absoluta necessidade e universalidade, mas seria mesmo uma ontologia, isto é, um conhecimento produtor de seres. Como este não é o nosso caso, esta lógica nos serve apenas para avaliar "a concordância de um conhecimento com as leis gerais e formais do entendimento e da razão" (Kant, 1997, B84); se o caso fosse de um conhecimento simplesmente intelectual, o critério de verdade da lógica seria, então, não critério, mas a própria Verdade.

Nesse sentido, afirmávamos que a $C R P$ pode ser compreendida como um tratado de metafísica e, de fato, o próprio Kant concorda com isso quando escreve que a filosofia da razão pura pode ser chamada de metafísica, pois este nome pode

ser dado a toda a filosofia pura, compreendendo a crítica, para abranger tanto a investigação de tudo o que alguma vez pode ser conhecido a priori, como também a exposição do que constitui um sistema de conhecimentos filosóficos puros dessa espécie, mas que se distinguem de todo o uso empírico como também do uso matemático da razão (Id., B869).

Seguindo essa definição, Kant vai mais além e afirma que

a metafísica divide-se em metafísica do uso especulativo e metafísica do uso prático e é, portanto, ou metafísica da natureza ou metafisica dos costumes. A primeira contém todos os princípios da razão, derivados de simples conceitos (portanto com exclusão da matemática), relativos ao conhecimento teórico de todas as coisas; a segunda, os princípios que determinam a priori e tornam necessários o fazer e o não fazer (Ibid.).

A Lógica transcendental, em um sistema da metafísica, ocupa uma função ao mesmo tempo Lógica, Ontológica e Epistemológica, ainda que este último conceito não nos seja de uso lícito. Do ponto de vista lógico, ela demonstra sua necessidade; como Ontologia, a sua possibilidade; e como conhecimento, a sua realidade. Esta base metafísica, em sua necessidade, aplicada à natureza do conhecimento da realidade fenomênica, gera a metafísica da natureza (sua realidade); aplicada à razão prática pura, a metafísica dos costumes (sua possibilidade); juntas formam a totalidade do conhecimento de pura razão - filosofia. Com efeito, isto explica porque Kant pode falar na Fundamentação da metafísica dos costumes de que "tudo na natureza age segundo 
leis"(Kant, 1974, p.217) e na CRP de leis gerais e formais do entendimento e da razão e também na Crítica da razão prática, na qual a razão proclama

uma lei para todos os seres racionais na medida em que eles, em geral, tem uma vontade, isto é, uma faculdade de determinar a sua causalidade pela representação de regras, por conseguinte, enquanto são capazes de ações segundo princípios, portanto, também segundo princípios práticos a priori (1999, A57).

Isso é possível porque as leis são as mesmas, ainda que aplicadas a objetos diferentes. São pois as leis da lógica.

Chegamos, portanto, em um ponto crucial para a nossa investigação. Com efeito, tanto a primeira crítica quanto a segunda podem ser compreendidas, de acordo com o que vimos, como obras cujo conteúdo pode ser estabelecido como metafísico. Nesse sentido, metafísica quer aqui designar tanto os alicerces do nosso saber e das coisas em geral quanto "o conhecimento filosófico derivado da razão pura, em encadeamento sistemático" (Kant, 1997, B869). O importante aqui é, porém, notar a consequência que se retira desta definição, pois a metafísica de Kant, isto é, a primeira e a segunda crítica, porque tratam ambas da razão pura, tem seu fundamento na Lógica transcendental, na medida em que é esta lógica que estabelece a possibilidade, a validade e os limites do conhecimento. Porque tal lógica não abstrai de seus conteúdos, ela pode fundamentar uma metafísica positiva. Porém, porque essa mesma lógica tem, por sua vez, o seu fundamento na lógica geral, na qual abstrairmos de todos os seus conteúdos, e na qual consideramo-la somente quanto à forma, a lógica geral pode ser definida, do ponto de vista transcendental, como uma metafísica negativa, isto é, que, apesar de não poder dizer o que é seu objeto, pode, porém, dizer o que ele não é.

Em outras palavras, porque a $C R P$ quer estabelecer os limites e possibilidades do conhecimento racional em geral, e não só humano, a lógica geral pode ser afirmada como uma metafísica positiva possível para todos os seres racionais em geral. Ao passo que, para nós, na medida em que ela apenas não deve se contradizer, embora não nos possa dizer nada do que sejam os objetos, pode ser real como metafísica negativa. Isto quer dizer que, se nós apenas podemos conhecer mediante a síntese realizada pelo entendimento entre conceito e intuição, não podemos, entretanto, afirmar que outros seres racionais não conheçam simplesmente por meio do entendimento e da razão. Estes são, portanto, os dois lados da moeda, pois "quando se ultrapassa o círculo da experiência, há a certeza de não ser refutado pela experiência” (Id., B8).

Com isso, estamos tentando dizer que a Lógica transcendental da CRP fundamenta positivamente não só essa obra, mas também a CRPr. Além disso, que a lógica geral, ao fundamentar por sua vez a Lógica transcendental, abre espaço para pensarmos uma Ontologia possível e, por isso, negativa, pois, "se a razão é inteiramente incapaz de, nesse campo, estabelecer proposições afirmativas, tão-pouco ou ainda menos é capaz de poder sobre tais questões afirmar algo de negativo" (Ibid., B781). Com o acréscimo de que, no caso em que o conhecimento pelo entendimento puro fosse possível, a verdade, enquanto 'principal perfeição' e "mais importante condição negativa" (Kant, 1992, A51), seria não só a Verdade, mas também o Bem, o Belo, o Perfeito..., pois seria, nesse conhecimento de pura razão, produtora de Ser. Mas esse não é o nosso caso.

Conclui-se que a CRP, em sua Lógica transcendental, traz o fundamento tanto para ela, enquanto metafísica da natureza, quanto para a $C R P r$, enquanto metafísica dos costumes, e que estas, por sua vez, buscam o seu fundamento na lógica geral, tal como apresentada por Kant em seu Manual. Isto quer dizer que a lógica geral fundamenta não só toda a Filosofia transcendental, enquanto "conhecimento que em geral se ocupa menos dos objetos, que do nosso modo de os conhecer, na medida em que este deve ser conhecido a priori" (Kant, 1997, B25), mas também toda a filosofia da razão pura em 
geral, enquanto modo possivel de conhecer imediatamente pelo entendimento e pela razão. A Filosofia transcendental, portanto, "é a ideia de uma ciência para a qual a crítica da razão pura deverá esboçar arquitetonicamente o plano total, isto é, a partir de princípios, com plena garantia da perfeição e solidez de todas as partes que constituem esse edifício" (Id, B27).

\section{OS PRINCÍPIOS DA LÓGICA COMO FUNDAMENTO METAFÍSICO}

Segundo Kant, em seu Manual de Lógica, a lógica é a "ciência das leis necessárias do entendimento e da razão, ou (...) da mera forma do pensamento em geral" (A4). O filósofo admira-se que ela, "desde remotos tempos, seguiu a via segura, pelo fato de desde Aristóteles, não ter dado um passo atrás. (...) Também é digno de nota que não tenha até hoje progredido, parecendo, por conseguinte, acabada e perfeita"(Kant, 1997, BVIII). Com efeito, "os limites da lógica estão rigorosamente determinados por se tratar de uma ciência que apenas expõe minunciosamente e demonstra rigorosamente as regras formais de todo o pensamento" (Id.). Mais que uma ciência, "a Lógica é um autoconhecimento do entendimento e da razão (...), mas unicamente segundo a forma" (Kant, 1992, A7). Por fim e de modo mais completo, Kant define a Lógica nos seguintes termos:

A Lógica é uma ciência, não segundo a matéria, mas segundo a mera forma; uma ciência a priori das leis necessárias do pensamento, mas não relativamente a objetos particulares, porém a todos os objetos em geral; portanto uma ciência do uso correto do entendimento e da razão em geral, mas não subjetivamente, quer dizer, não segundo princípios empíricos, sobre a maneira como pensa o entendimento, mas, sim, objetivamente, isto é, segundo princípios a priori de como ele deve pensar (Id., A9-10).

A Lógica, enquanto metafísica, por ser 'uma ciência do uso correto do entendimento e da razão em geral', não se limita ao nosso modo de conhecer, ou seja, mediante a síntese entre intuição e conceito, mas dita as regras para a verdade do pensamento racional em geral. Estas regras são estabelecidas na forma de princípios, que, segundo Kant, serão critérios formais e universais da verdade. Com efeito, a Lógica deve, antes de tudo, fornecer "as regras da concordância do conhecimento com as leis do entendimento e da razão" (Ibid., A8). Esta concordância, porém, não pode ser buscada pelo lado da matéria do conhecimento, pois um critério de verdade que deva ser universal, tem, antes de tudo, que abstrair da diferença entre os objetos. Precisamente por isso, a Lógica, para nós, só pode fornecer critérios universais para a verdade quanto à forma do conhecimento, ou seja, ela não pode afirmar a concordância do conhecimento com o objeto, mas pode se pronunciar acerca da sua concordância consigo própria (Ibid., A71-72). A Lógica, portanto, fornece, para nós, quanto à matéria do conhecimento, apenas o critério negativo da verdade, já que, para avaliar positivamente sobre a concordância do conhecimento com o objeto, precisaríamos ter acesso ao objeto tal como é em si mesmo, coisa que o idealismo nos pró́be.

Nesse sentido, a verdade apenas pode se referir ao acordo do conhecimento consigo próprio.

Esses critérios universais e formais não são, é verdade, suficientes para a verdade objetiva, mas devem, no entanto, ser considerados como a conditio sine qua non dos mesmos. Pois, antes de perguntar se o conhecimento concorda com o objeto, deve vir antes a questão se ele concorda consigo próprio (segundo a forma). E isto é assunto da Lógica (Ibid., A72-73).

Segundo Kant, os critérios formais da Lógica são: o princípio de não 
contradição; e o princípio de razão suficiente. Pelo primeiro fica estabelecida a exigência de

que ele [o conhecimento] seja logicamente possível, quer dizer, que ele não se contradiga. Mas essa característica da verdade interna é tão-somente negativa; pois é verdade que um conhecimento que se contradiz é falso; mas, se ele não se contradiz, nem por isso é sempre verdadeiro (Ibid.).

Pelo segundo, é exigido do conhecimento "que ele seja logicamente fundado, quer dizer, que ele tenha: (a) razões em que se funde e (b) não tenha consequências falsas" (Ibid.). Se o primeiro critério da verdade lógica é apenas negativo, o segundo, no entanto, é um "critério da lógica externa ou da racionalidade, o qual concerne à conexão lógica de um conhecimento com razões e consequências, [e] é positivo" (Ibid.).

Os princípios da lógica dizem respeito, pois, às diversas formas de relação entre o conhecimento e o objeto e, ao fim e ao cabo, Kant nos apresenta aquelas três formas que na lógica formal deverão ser os critérios de verdade puramente formais ou lógicos e que são:

1) o princípio de contradição e da identidade, mediante o qual está determinada a possibilidade interna de um conhecimento para juízos problemáticos;

2) o princípio de razão suficiente, no qual se baseia a realidade (lógica) de um conhecimento;

3) o princípio do terceiro excluido, no qual se funda a necessidade (lógica) de um conhecimento - o fato de que necessariamente se deva julgar assim e não de outro modo, isto é, que o contrário seja falso (Ibid., A75-76).

$\mathrm{O}$ conhecimento do objeto reúne a matéria que provém da sensibilidade com as formas puras do entendimento. Quanto à matéria, como vimos, não podemos estabelecer nenhum critério universal de verdade. Assim, só podemos falar de critérios universais de verdade com relação à forma do conhecimento. Esta forma, porém, não está no objeto, mas no próprio entendimento e é válida para todos os seres racionais em geral. Portanto, só podemos falar de concordância entre as leis da Lógica e a forma do próprio entendimento.

$\mathrm{Na}$ Lógica, entretanto, como é considerada a ciência das leis do entendimento e da razão, deve então a concordância de suas leis com a forma do conhecimento nada mais ser do que a "concordância do conhecimento consigo próprio" (Ibid., A72). Com efeito, no paralelismo entre as leis da Lógica e a forma do conhecimento, o quê está implicado, de fato, é a relação entre a produção do conceito lógico e a do objeto fenomênico. Da concordância entre ambas extraímos tanto os critérios negativos da realidade do objeto, quanto a possibilidade da Lógica como Metafísica. Se é verdade que sobre isso não podemos afirmar nada, contudo também não podemos negar - fica aberta a possibilidade.

Assim, o primeiro dos critérios formais de verdade apresentados logo acima - o princípio de contradição e de identidade - diz respeito precisamente à relação entre os princípios da lógica e a forma do conhecimento. Nesse sentido, para o conhecimento (verdadeiro) do objeto, eles não podem se contradizer e, por isso, é apenas um critério negativo. De sua não contradição, porém, podemos pensar a possibilidade da identidade tanto entre matéria e forma do conhecimento, ainda que não possamos disso nada saber, quanto entre a forma do pensamento em geral e uma possivel realidade metafísica dessas formas. Isto tudo, entretanto, para Kant, seria mera especulação sem suporte algum em nosso modo de conhecer, o único que nos é possível. Apesar disso, não nos é proibido pensar, ainda que não possamos saber, uma estreita relação entre 
Lógica, Metafísica e Ontologia; entre a validade de um conhecimento, a descoberta da estrutura da realidade fenomênica e o acesso ao Ser.

O segundo e o terceiro princípios apresentados acima já não dizem respeito diretamente à concordância das leis da Lógica com a forma do conhecimento, mas à relação interna à própria Lógica. Com efeito, o princípio de razão suficiente oferece o critério positivo para a estrutura interna da própria Lógica, a sua racionalidade portanto. O princípio do terceiro excluído, o critério negativo. Indiretamente, na relação com o sujeito cognitivo, devido ao paralelismo entre a forma da Lógica e a forma do conhecimento, o princípio de razão suficiente também fornece para essa o princípio de racionalidade. $\mathrm{Na}$ especulação, por outro lado, esse mesmo princípio funciona da mesma forma, porém, ocupando não uma função positiva, mas negativa; demonstrando apenas a forma como a Lógica e o conhecimento não podem se estruturar.

Segundo Kant,

a lógica geral está edificada sobre um plano que se ajusta exatamente à divisão das faculdades superiores do conhecimento. São estas o entendimento, a faculdade de julgar e a razão. Essa doutrina trata, pois, na sua analítica, de conceitos, juízos e raciocínio, em conformidade com as funções e ordem dessas faculdades do espírito, compreendidas sob a denominação lata de entendimento em geral (Kant, 1997, B169).

Quando Kant se refere ao conhecimento de pura razão, está se referindo à unidade de conhecimento tanto teórico como prático. Com efeito, se a CRP trata do conhecimento teórico e a $C R P r$ do conhecimento prático, ambas são ainda uma e mesma razão, pois "a razão pura constitui uma unidade completamente à parte e autônoma, na qual, como um corpo organizado, cada membro existe para todos os outros e de todos para cada um" (Id., BXIII). Nesse sentido, frente ao plano geral da razão pura,

uma crítica que limita a razão especulativa é, como tal, negativa, mas na medida em que anula um obstáculo que restringe ou mesmo ameaça aniquilar o uso prático da razão, é de fato uma utilidade positiva e altamente importante, logo que nos persuadirmos de que há um uso prático absolutamente necessário da razão pura (o uso moral) (Ibid., BXV).

Com efeito, o problema geral da razão pura "está contido na seguinte pergunta: como são possíveis juízos sintéticos a priori?" (Ibid., B19). Por outro lado, a CRPr tem a preocupação de "demonstrar que existe uma Razão pura prática" (Kant, 1999, A3). Assim, de acordo com a divisão feita por Kant, a primeira crítica se ocupa tanto com o entendimento quanto com a faculdade de julgar e os seus produtos: os conceitos e juízos. A segunda crítica, porém, já se ocupa apenas com a razão e com os raciocínios ou inferências. O conhecimento de ambas, reunidos, formam o todo do conhecimento de pura razão. Do ponto de vista do todo, a primeira crítica oferece os critérios negativos do conhecimento, mostrando-lhes apenas os seus limites; já a segunda, pelo contrário, porque permite que o conhecimento de razão pura se estenda para além dos limites colocados pela $C R P$, oferece critérios positivos. Em conjunto, portanto, elas oferecem, em outros termos, matéria e forma do conhecimento de pura razão.

Voltando agora à Lógica, como ao fundamento metafísico da filosofia kantiana, poderemos nos deparar com elementos verdadeiramente esclarecedores da arquitetônica da Filosofia crítica. Vimos que os princípios lógicos são critérios gerais de verdade e vimos também que na lógica tanto os juízos como as inferências possuem princípios. Isto nos conduz, portanto, a pensarmos que exatamente o mesmo ocorre na filosofia teórica e na filosofia prática de Kant. Vamos ver isso mais de perto.

Com relação aos juízos, na Lógica, Kant define os seus princípios, pois, como 
“juízos imediatamente certos a priori (...) na medida em que outros juízos possam ser provados a partir deles, não podendo eles próprios, porém, serem subordinados a nenhum outro" (Kant, 1992, A172). Na CRP, o filósofo define os princípios do entendimento puro praticamente nos mesmos termos, vejamos: "os princípios a priori têm este nome, não só porque contêm em si os fundamentos de outros juízos, mas também porque não assentam em conhecimentos mais elevados e de maior generalidade" (Kant, 1997, B188). As definições de princípio de juízo lógico e de princípio do entendimento puro estão muito próximas. Os princípios do entendimento são a unidade mais elevada à qual o conhecimento pode elevar-se e, por isso, eles não podem ser provados, pois possuem "a propriedade especial de tornar possível o fundamento de sua própria prova, a saber, a experiência e nesta deve estar sempre pressuposta" (Id., B765). Ora, é precisamente a possibilidade do conhecimento de experiência que Kant busca com a primeira crítica, isto é, os famosos juízos sintéticos $a$ priori. Os princípios, como vimos na Lógica, são critérios de verdade. Portanto, não é de estranhar que a Lógica transcendental, na medida em que supõe a lógica geral, também utilize os seus princípios como critérios de verdade ou validade - aqui já não há mais diferença entre elas.

Nesse sentido, distinguindo os juízos em analíticos e sintéticos, Kant estabelecerá, na $C R P$, os seguintes princípios para cada um deles: para os juízos analíticos, "o princípio de contradição é o princípio universal e plenamente suficiente de todo o conhecimento analítico" (Ibid., B191). Com efeito, porque no conhecimento analítico o predicado pertence necessariamente ao sujeito, não podendo haver contradição entre eles, o princípio de não contradição, enquanto critério de verdade, abre o horizonte para um critério de verdade positivo - ao princípio de identidade. No conhecimento sintético, pelo contrário,

tenho de sair do conceito dado para considerar, em relação com ele, algo completamente diferente do que nele já estava pensado; relação que nunca é, por conseguinte, nem uma relação de identidade, nem de contradição, e pela qual, portanto, não se pode conhecer, no juízo em si mesmo, nem a verdade nem o erro (Ibid., B193).

Não podendo buscar a concordância de sujeito e objeto nos próprios conceitos e o conhecimento sintético dizendo respeito à experiência, Kant pensa, então, que essa concordância pode ser encontrada na relação do conhecimento com a experiência. Com efeito, os juízos sintéticos a priori são possíveis

quando referimos as condições formais da intuição a priori, a síntese da
imaginação e a sua unidade necessária numa apercepção transcendental, a um
conhecimento de experiência possível em geral e dizemos: as condições da
possibilidade da experiência em geral são, ao mesmo tempo, condições da
possibilidade dos objetos da experiência e tem, por isso, validade objetiva num
juízo sintético a priori (Ibid., B197).

Os juízos teóricos dizem respeito à relação do conhecimento com seu objeto e possuem seus critérios de verdade estabelecidos pela Lógica. Assim, para juízos analíticos, o princípio de contradição fornece o critério negativo de verdade e o princípio de identidade, o critério positivo. Para juízos sintéticos a priori, ao contrário, nenhum desses critérios pode ser utilizado. Como, porém, esses são juízos a priori, isto é, formais e como os elementos formais do conhecimento são ao mesmo tempo transcendentais, ou seja, dizem respeito à estrutura cognitiva do próprio sujeito do conhecimento, então pode Kant estabelecer como único critério para a verdade formal desses juízos, a implicação entre a forma do conhecimento e a forma do objeto do conhecimento. Nesse sentido, se aqui já não são aplicáveis os mesmos critérios 
utilizados para os juízos analíticos, contudo não lhes falta base de apoio na Lógica. Com efeito, o princípio lógico de razão suficiente preenche a exigência de um critério positivo e o princípio do terceiro excluído, o critério negativo de verdade. Portanto, o princípio dos juízos sintéticos a priori possui sua validade atestada, negativamente, pelo princípio de não contradição, critério universal de todos os juízos; e, positivamente, pelo princípio de razão suficiente, cuja função consiste na ligação entre causa e efeito.

Já na filosofia prática, apesar de Kant dedicar grande parte de sua investigação para provar a possibilidade do imperativo categórico, que, em termos de juízo, corresponde às proposições sintéticas a priori para o conhecimento prático (Kant, 1974, $2^{\mathrm{a}}$ seção), o seu objetivo, entretanto, é "demonstrar que existe uma razão pura prática" (Kant, 1999, A3), ou seja, que a liberdade da vontade seja possível.

Os princípios práticos são, segundo Kant, as proposições "que contêm uma determinação geral da vontade" (Id., A35). Os princípios práticos dividem-se em máximas, "quando a condição é considerada pelo sujeito como válida unicamente para a sua vontade", e em leis "quando essa condição é reconhecida como objetiva, isto é, válida para a vontade de todo o ser racional" (Ibid.). Como o interesse de Kant recai sobre a possibilidade do uso puro da razão, as máximas não são problemas, pois deixam-se explicar com base na subjetividade de cada sujeito. As leis, porém, se forem possíveis, já não podem conter nada de subjetivo, portanto, nenhuma matéria do querer.

$\mathrm{Na}$ filosofia teórica, o problema girava em torno da relação entre sujeito e predicado dos juízos. Na filosofia prática, ao contrário, o problema concerne à relação entre juízos, pois lá o filósofo se ocupava com a possibilidade de uma forma determinada de juízos, e, aqui, com uma forma particular de raciocínios. Na primeira, ao conhecimento do que é, nesta, ao que deve ser.

Com relação aos juízos, na primeira crítica, Kant havia identificado três formas, a saber: analíticos, sintéticos a priori e sintéticos a posteriori. Nela, os juízos se referem à possibilidade do conhecimento teórico. Ora, a $C R P r$ também se refere à possibilidade do conhecimento, porém, prático. Mas o que sejam os imperativos ou o lugar que ocupam não é tão claro assim, pois Kant não nos esclarece. Kant não, mas o seu Manual de lógica (1992) sim!

$\mathrm{Na}$ seção sobre as inferências da razão, encontramo-las divididas segundo a relação em categóricas, hipotéticas e disjuntivas (Kant, 1992, A190). Nesse mesmo parágrafo, sob o verbete observação, encontramos, ainda, o seguinte esclarecimento:

as inferências da razão não podem ser divididas nem segundo a quantidade (...); nem relativamente à qualidade (...); nem, finalmente, com respeito à modalidade (...). Portanto, resta apenas a relação como único fundamento possível da divisão das inferências da razão (Id., A191).

Kant não esclarece em lugar algum das críticas porque os imperativos só apresentam aquelas formas. O seu Manual de lógica, porém, sim.

Com efeito, as inferências da razão compõem-se de: 1) uma regra universal, chamada maior; 2) a proposição que subsume um conhecimento à condição da regra e se chama menor; 3) a proposição que afirma ou nega do conhecimento subsumido o predicado da regra e se chama conclusão (Ibid., A188-189). Nesse sentido, as inferências não podem ser divididas segundo a quantidade, porque toda maior já é uma regra e, assim, universal. Nem segundo a qualidade, porque é indiferente se a conclusão é afirmativa ou negativa e nem segundo a modalidade, porque a conclusão é sempre necessária, portanto, apodíctica (Ibid., A191). Resta, assim, apenas a categoria de relação para a divisão entre as diferentes formas de inferências e para a aplicação do imperativo categórico às máximas da vontade.

Como a nossa preocupação é com os imperativos categóricos, vamos nos ocupar apenas com eles e, se nossas conclusões forem corretas, a aplicação aos outros 
imperativos não será problema, podendo deixá-la em segundo plano ou por conta do leitor.

Segundo Kant, a única das inferências categóricas que é legítima é a da primeira figura. É aquela na qual o termo médio ocupa, na premissa maior, o lugar de sujeito e, na menor, o lugar de predicado. A sua regra é formulada nos seguintes termos: tem de ser

a maior uma proposição universal e a menor uma proposição afirmativa. E, como esta deve ser a regra universal de todas as inferências categóricas da razão em geral, resulta daqui que a primeira figura é a única legítima, servindo de fundamento a todas as demais (Ibid., A197).

O imperativo categórico, por sua vez, é formulado nos seguintes termos: "age de tal modo que a máxima da tua vontade possa valer ao mesmo tempo como princípio de uma legislação universal" (Kant, 1999, A54). Ora, a máxima, elevada a princípio universal, cumpre as exigências do primeiro componente da inferência (a premissa maior), isto é, a exigência de uma regra universal. O segundo componente (a premissa menor) deve ser uma proposição que subsuma um conhecimento à condição da regra. Ora, "todas as regras (juízos) contêm uma unidade objetiva da consciência do múltiplo do conhecimento" (Kant, 1992, A90). Essa unidade é, pois, o eu penso da primeira crítica, que, subsumido pela regra, nos fornece a segunda premissa, na qual o conceito do sujeito da premissa maior será, nessa, o conceito do predicado. O terceiro componente (a conclusão) é uma proposição que afirma ou nega do conhecimento subsumido o predicado da regra. Portanto, a conclusão terá a unidade do eu penso relacionada afirmativamente ou negativamente com o predicado da regra.

Assim, o imperativo categórico se mostra como a exigência de um raciocínio que discerne a "necessidade de uma proposição pela subsunção de sua condição a uma regra geral" (Kant, 1999, A187) e, precisamente esta, é também a definição de inferências da razão. Por outro lado, "como os antecedentes ou premissas constituem a matéria, e a conclusão, na medida em que contêm a consequência, a forma das inferências da razão"(Id., A189). Como a forma não é buscada na natureza, mas é $a$ priori, então pode Kant também afirmar a possibilidade de uma razão pura prática e, consequentemente, da liberdade da vontade.

Os imperativos são definidos na Lógica como proposições que enunciam "uma possível ação livre pela qual um certo fím deve ser realizado" (Ibid., A135). Tais imperativos são categóricos quando obedecem à seguinte lei: "age de tal modo que a máxima da tua vontade possa valer sempre ao mesmo tempo como princípio de uma legislação universal" (Ibid., A54). Ora, da natureza não podemos derivar nenhuma lei, assim, frente ao fato da razão, para justificar 'uma possível ação livre' e, portanto, de um uso puro da razão, temos de pressupor a ideia da liberdade da vontade.

A exigência de não contradição na vontade deixa-se explicar pela universalização da máxima, pois, no momento que a universalizo, também me ponho sob a regra e já não posso deduzir legitimamente a conclusão senão conforme as leis da lógica. Junto a isso, acrescenta-se o paralelismo entre razão e vontade, e teremos uma vontade que não pode se contradizer porque não pode concluir sua inferência legitimamente senão pelas leis da Lógica.

Assim, "a inferência da razão toma como premissa uma regra universal e uma subsunção à condição da regra. Dessa maneira, discernimos a conclusão a priori, não no singular, mas enquanto contida no universal e necessária sob uma certa condição" (Kant, 1992, A188). A exigência de não contradição na vontade é, portanto, o mesmo princípio de não contradição enunciado na Lógica.

Segundo Kant dizia antes, à verdade lógica de um conhecimento pertencem duas coisas: 
Primeiro: que ele seja logicamente possível, quer dizer, que não se contradiga. Mas essa característica da verdade lógica interna é tão-somente negativa; pois é verdade que um conhecimento que se contradiz é falso; mas, se ele não se contradiz, nem por isso é sempre verdadeiro.

Segundo: que ele seja logicamente fundado, quer dizer, que ele tenha: (a) razões em que se funde e (b) não tenha consequências falsas.

Este segundo critério da verdade lógica externa ou da racionalidade, o qual concerne à conexão lógica de um conhecimento com razões e consequências, é positivo (Id., A73).

\section{CONCLUSÃo}

Chegados aqui, pensamos ter demonstrado suficientemente que o fundamento da filosofia teórica e prática de Kant reside na estrutura dos princípios da Lógica e, assim sendo, a própria Lógica acaba por elevar-se à condição de fundamento metafísico da filosofia kantiana e estrutura da realidade fenomênica. Com isso, a explicação tanto da lei da causalidade natural como da causalidade pela liberdade, deixam-se compreender pela aplicação do princípio de razão suficiente ou à filosofia teórica ou à filosofia prática. A ideia de sujeito lógico, por sua vez, informa as noções de sujeito epistemológico e de sujeito prático. Naquele como sujeito dos juízos teóricos, neste como premissa menor. A cópula, na primeira crítica, a qual permite a ligação entre sujeito e predicado segundo regras, é "a forma, pela qual se vê determinada e expressa a relação (de acordo ou conflito) entre o sujeito e o predicado" (Ibid., A162-163) e representa a espontaneidade do pensamento, enquanto representação da liberdade na filosofia teórica. Já a conclusão das inferências da razão, que é definida como a forma dos raciocínios em contraposição à matéria, formada pelas premissas maior e menor, na segunda crítica, representa a autonomia como representação da liberdade na filosofia prática. Precisamente por isso pode Kant dizer que a liberdade, tanto como espontaneidade quanto como autonomia, é uma liberdade segundo leis. As leis da lógica, por isso, adquirem matizes metafísicos, epistemológicos, práticos e antropológicos e o princípio lógico de razão suficiente acaba explicando tanto a categoria de causalidade na filosofia teórica quanto a inferência da conclusão na filosofia prática; ou seja, o princípio de razão suficiente fundamenta ao mesmo tempo a ideia de necessidade segundo leis da natureza e a ideia de necessidade segundo as leis da liberdade. Assim, os princípios de contradição e razão suficiente são, pois, fundamentais, porque lhes oferecem os critérios gerais para a verdade. Verdade, que, positivamente, deve ser compreendida como a concordância do conhecimento com o objeto. Concordância da qual a perfeição do conhecimento surge mediante a união harmônica entre multiplicidade e unidade (Ibid., A51), motivo pelo qual Kant glorifica a verdade como "a principal perfeição, porque ela é o fundamento da unidade, graças à relação do nosso conhecimento com o objeto" (Ibid.). A Verdade, portanto, nesse último sentido, se reveste de caráter onto-lógico.

\section{REFERÊNCIAS}

KANT, Immanuel. Lógica. Rio de Janeiro: Tempo brasileiro, 1992.

KANT, Immanuel. Crítica da Razão prática. Lisboa: Edições 70, 1999.

KANT, Immanuel. Crítica da Razão pura. Lisboa: Fundação Calouste Gulbenkian, 1997.

CAYGILL, Howard. Dicionário Kant. Rio de Janeiro: Jorge Zahar, 2000.

KANT, Immanuel. Prolegômenos. São Paulo: Abril cultural (Coleção Os Pensadores), 1974. 